\title{
Electrochemistry of Deferiprone as an Orally Active Iron Chelator and HIV-1 Replication Inhibitor and its Determination
}

\author{
H. Yadegari, ${ }^{a}$ A. Jabbari, ${ }^{* a}{ }^{a}$ H. Heli, ${ }^{b}$ A. A. Moosavi-Movahedi ${ }^{b}$ and S. Majdi ${ }^{a}$ \\ ${ }^{a}$ Department of Chemistry, Faculty of Science, K. N. Toosi University of Technology, \\ P.O. Box 16315-1618, Tehran, Iran \\ ${ }^{b}$ Institute of Biochemistry and Biophysics, University of Tehran, Tehran, Iran
}

\begin{abstract}
O comportamento eletroquímico da deferiprona, droga anti-talassêmica e anti-replicação do HIV foi investigado, por voltametria cíclica (VC), utilizando um eletrodo de platina. Observaram-se dois picos anódicos irreversíveis para a deferiprona, em tampão acetato $(\mathrm{pH} 4,0) \operatorname{com} E_{1}^{0}=875 \mathrm{mV}$ e $E_{2}^{0}=1235 \mathrm{mV}(v \mathrm{~s} . \mathrm{Ag} / \mathrm{AgCl})$ em velocidade de varredura de $50 \mathrm{mV} \mathrm{s}^{-1}$. Os estudos de voltametria cíclica indicaram que o processo de oxidação é irreversível e controlado por difusão. Foram encontrados, para a deferiprona, coeficientes de difusão e de transferência de elétrons de $3,50 \times 10^{-6} \mathrm{~cm}^{2} \mathrm{~s}^{-1}$ e 0,57 , respectivamente. Foi desenvolvido um procedimento sensível, simples e rápido, utilizando voltametria de pulso diferencial. Utilizando este método, a deferiprona pode ser determinada com um limite de detecção de $1,43 \times 10^{-5} \mathrm{~mol} \mathrm{~L}^{-1}$. É descrita a aplicabilidade do método em ensaios diretos em soro humano enriquecido, fluidos urinários e em comprimidos comerciais.
\end{abstract}

The electrochemical behavior of the anti-thalassemia and anti-HIV replication drug, deferiprone, was investigated by cyclic voltammetry $(\mathrm{CV})$ at a platinum electrode. In an acetate buffer solution, $\mathrm{pH}=4.0$, two irreversible anodic peaks for deferiprone, with $E^{0}{ }_{1}=875 \mathrm{mV}$ and $E^{0}{ }_{2}=1235 \mathrm{mV}(v s . \mathrm{Ag} / \mathrm{AgCl})$ appeared at a potential sweep rate of $50 \mathrm{mV} \mathrm{s}^{-1}$. Cyclic voltammetric study indicated that the oxidation process is irreversible and diffusion-controlled. The diffusion and the electron transfer coefficients of deferiprone were found to be $3.50 \times 10^{-6} \mathrm{~cm}^{2} \mathrm{~s}^{-1}$ and 0.57 , respectively. A sensitive, simple and time-saving differential pulse voltammetric procedure was developed. Using our proposed method, deferiprone can be determined with a detection limit of $1.43 \times 10^{-5} \mathrm{~mol} \mathrm{~L}^{-1}$. The applicability of the method to direct assays of spiked human serum and urine fluids, and to commercial tablets, is described.

Keywords: deferiprone, anti-thalassemia drug, platinum electrode, iron chelator, HIV-1 replication inhibitor

\section{Introduction}

Deferiprone (1,2-dimethyl-3-hydroxypyridin-4-one, Scheme 1) is the first oral iron chelator to be used clinically, mainly in thalassemia patients. ${ }^{1,2}$ Deferiprone belongs to the family of the alpha-ketohydroxypyridines, a relatively new class of chelating agents, some of which are naturally occurring. These chelators have a high affinity for binding iron, and are able to remove it from proteins that are transporting and storing it in the body, largely sparing other biologically important metals. They are stable in conditions that exist in the human digestive system and are readily absorbed. Deferiprone can remove excess iron from various

\footnotetext{
*e-mail: jabbari@kntu.ac.ir
}

parts of the body of iron-loaded patients, including liver and, particularly, heart. ${ }^{1}$ This drug is also used worldwide to treat cancer, leukemia, in hemodialysis and other diseases. It is worthy noting that the drug deferiprone may be used in the detoxification of other metals, such as aluminum in hemodialysis patients, plutonium used in the nuclear industry and uranium used by the military. ${ }^{3-5}$

Iron is also involved in replication of the human immunodeficiency virus type 1 (HIV-1). ${ }^{6}$ Iron chelators such as deferiprone inhibit replication of HIV-1 through several routes. Deferiprone can inhibit nuclear factor- $\mathrm{KB}$ activation and subsequent replication of human immunodeficiency virus type $1 .^{7}$ Deferiprone can also render iron-dependent ribonucleotide reductase inactive, thereby inhibiting DNA synthesis and therefore HIV replication. ${ }^{8}$ 
<smiles>Cc1c(O)c(=O)ccn1C</smiles>

Scheme 1.

Drug analysis has an extensive impact on public health. In order to minimize the risk of side effects, ${ }^{9,10}$ to optimize further dosing intervals ${ }^{11}$ and to monitor the L1 therapy, ${ }^{12}$ methods for the accurate measurement of the drug are necessary. It was previously found that the chromatography of the 3-hydroxypyridin-4-ones is difficult on normal octadecylsilica (ODS) columns as the analytes are often characterized by broad asymmetrical and sometimes multiple peaks. ${ }^{13}$ Goddard and Kontoghiorghes ${ }^{14}$ described a HPLC based method to assay deferiprone in serum and urine. Dresow et al. ${ }^{15}$ also describe a HPLC method for the determination of deferiprone in serum and urine samples and a HPLC based assay to determine the iron excretion (due to deferiprone therapy) by measuring urinary $\mathrm{Fe}$-(deferiprone) complex concentration. Polarography and voltammetry can be considered as convenient alternatives to routinely employed analytical methods, in that they present the great advantage of permitting a direct, simple and rapid determination requiring a minimum volume of sample. Electrochemical techniques have also been used for the determination of a wide range of drug compounds. They have the advantage of not requiring, in most instances, derivatization, and they are less sensitive to matrix effects than other analytical techniques. Additionally, electrochemical techniques allow the study of the redox mechanism of the drugs. Redox properties of drugs can provide insight into their metabolic fate, their in vivo redox processes and their pharmacological activity. ${ }^{16-22}$

Voltammetric oxidation and electrochemical determination of deferiprone on a platinum surface have not, to the best of our knowledge, been reported in the literature. In the present work, we have studied the electrochemical behavior of deferiprone at a platinum electrode, with the aim of developing an electroanalytical procedure for quantification of deferiprone in both bulk form and pharmaceutical formulation.

\section{Experimental}

All chemicals used in this work were of analytical reagent grade from Merck. Deferiprone was kindly supplied by Arasto Pharmaceutical Chemicals Inc., Tehran, Iran. The deferiprone tablets were kindly supplied by Avicenna Laboratories, Saveh, Iran.
The standard solution of deferiprone was prepared by dissolving an accurate mass of the bulk drug in an appropriate volume of $100 \mathrm{mmol} \mathrm{L}^{-1}$ acetate buffer solution, $\mathrm{pH} 4.0$ (which was also used as supporting electrolyte), and then stored in the dark at $4{ }^{\circ} \mathrm{C}$. Additional diluted solutions were prepared daily by accurate dilution just before use. Deferiprone solutions were stable and their concentrations did not change with time.

Drug-free serum samples were obtained from healthy male volunteers and stored frozen until the assay. The serum samples were diluted (1:7) with the supporting electrolyte and filtrated through a $30 \mathrm{kDalton}$ filter to produce proteinfree human serum. Various portions of stock deferiprone solution were transferred into $10 \mathrm{~mL}$ volumetric flasks containing $3.3 \mathrm{~mL}$ of the serum sample. These solutions were then diluted to the mark with the supporting electrolyte for preparation of spiked samples (final dilution of 1:20 with the supporting electrolyte). The protein-free spiked serum solutions were directly analyzed by the calibration method, according to our proposed procedure.

Urine samples taken from a healthy person were diluted (1:10) with buffer solution after adding an appropriate amount of deferiprone standard solution. The resulting solution was, then, directly analyzed, according to our proposed procedure, without any pretreatment or extraction steps.

For deferiprone determination in pharmaceutical preparations, an average mass of five tablets from the same batch was determined, then finely ground and homogenized in a mortar. The weighted amount of this powdered sample was used to prepare the sample solution, which was filtered and transferred to a volumetric flask. The volume was completed with the buffered electrolyte solution.

Electrochemical measurements were carried out in a conventional three-electrode cell (from Metrohm) powered by an electrochemical system comprising the AUTOLAB system with PGSTAT30 (Eco Chemie, Utrecht, The Netherlands). The system was run on a PC using the GPES 4.9 software. Acetate buffer solution, $\mathrm{pH} 4$.0, was used as a supporting electrolyte. It should be mentioned that $\mathrm{pH} 4.0$ was selected as a mean acidic medium due to the high solubility of deferiprone, in neutral $\mathrm{pH}$ the deferiprone solubility is very low. $\mathrm{An} \mathrm{Ag} / \mathrm{AgCl}$ with $\mathrm{KCl}$ $3.0 \mathrm{~mol} \mathrm{~L}^{-1}$ (from Metrohm) and a platinum disk $\left(3.0 \mathrm{~cm}^{2}\right.$ in surface area, from Azar Electrode Co., Iran) were used as reference and counter electrodes, respectively. The working electrode was a platinum disk (from Metrohm), exposing a surface area of $0.0314 \mathrm{~cm}^{2}$. For coulometric experiments, a low volume cell ( $5 \mathrm{~mL}$, Goldis Co., Iran); equipped with a platinum electrode $\left(3.0 \mathrm{~cm}^{2}\right.$ in surface area, from Azar Electrode Co., Iran) and a glassy carbon electrode (from Azar Electrode Co., Iran) as the working 
and counter electrodes, respectively, were employed. The typical concentration of deferiprone in the solution was $2.1 \mathrm{mmol} \mathrm{L}^{-1}$. The working potentials of 851 and $1268 \mathrm{mV}$ were used for the electrolysis processes. For differential pulse voltammetry (DPV) measurements, a pulse width of $25 \mathrm{mV}$, a pulse time of $50 \mathrm{~ms}$, and a scan rate of $10 \mathrm{mV} \mathrm{s}^{-1}$ were employed. Before measurement of each voltammogram, it is necessary to perform a polishing in the working electrode with $0.05 \mu \mathrm{m}$ suspension on alumina, on a polishing micro-cloth, followed by sonication for $3 \mathrm{~min}$ in an ultrasonic bath. The electrode was then introduced into the cell. Potential in the range of -300 to $1400 \mathrm{mV}$ in a regime of cyclic voltammetry was applied until a stable voltammogram was achieved. The solution $\mathrm{pH}$ was adjusted using a Metrohm 744 pH meter. All studies were carried out at room temperature.

\section{Results and Discussion}

Figure 1 shows a typical cyclic voltammogram of $4.5 \mathrm{mmol} \mathrm{L}^{-1}$ deferiprone in the acetate buffer solution, $\mathrm{pH}$ 4.0. For comparison, the cyclic voltammogram of the blank electrolyte is also shown. Deferiprone has presented two anodic peaks (a1 and a2) in the voltammogram, with potentials of $768 \mathrm{mV}$ and $1184 \mathrm{mV}$, respectively, at the potential sweep rate of $10 \mathrm{mV} \mathrm{s}^{-1}$. In the reverse sweep, however, no peaks appeared, indicating an irreversible heterogeneous electron transfer process for the oxidation of deferiprone at the platinum surface.

Controlled-potential coulometries were performed in the $5 \mathrm{~mL}$ buffer solution containing $2.1 \mathrm{mmol} \mathrm{L}^{-1}$ deferiprone, at 851 and $1268 \mathrm{mV}$. The consumed coulombic charge in each stage of electrolysis, calculated from coulogram ( $Q$ vs. $T$ curve) and the mole number of deferiprone electrolyzed in each stage was determined by cyclic voltammetry. Then the consumed coulombic curve versus mol number of deferiprone electrolysis was calculated and plotted for more than 15 stages of electrolysis (with an intercept of $2.097 C, \mathrm{R}=0.935, \mathrm{n}=18$ for peak a1 and an intercept of $4.063 C, \mathrm{R}=0.971, \mathrm{n}=16$ for peak a2). The charge consumptions for total electrolysis of the solution were derived from intercepts of these plots and the numbers of exchanged electrons were found to be 2.1 and 2.0, respectively. Therefore, deferiprone is oxidized via two two-electron steps.

A pseudo-steady-state current-potential curve recorded for the first step of oxidation of deferiprone (peak a1 in Figure 1) and a typical S-shape plot was obtained. The slope of the $E$ vs. $\log I$ plot was found to be $103.7 \mathrm{mV} \mathrm{dec}^{-1}$ for deferiprone (with aregression equation of $y=103.67 x+621.88$, $\mathrm{R}=0.995)$. Also, the electron transfer coefficient multiply

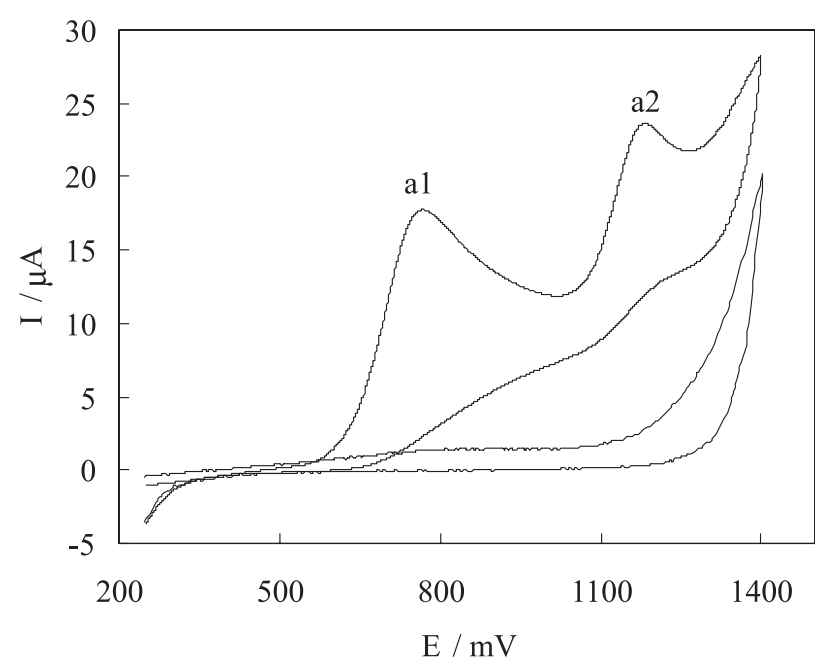

Figure 1. Cyclic voltammogram of $4.5 \mathrm{mmol} \mathrm{L}^{-1}$ deferiprone in the acetate buffer solution, $\mathrm{pH}=4.0$. Potential sweep rate was $10 \mathrm{mV} \mathrm{s}^{-1}$.

by the number of exchanged electrones $(\alpha n)$ was determined to be 0.57 .

The effect of potential sweep rate was studied in the range of 15 to $600 \mathrm{mV} \mathrm{s}^{-1}$ (Figure 2). As the potential sweep rate increased, both peak currents increased. Also, the peak potentials shifted to more positive values and no peak appeared in the reverse sweep, indicating the irreversible nature of the reaction processes. In addition, the peak currents depend linearly on the corresponding square root of potential sweep rate (with a regression equation of $y=12.62 x+11.75, R=0.999, n=11$, Figure 2 , inset), indicating a diffusion-controlled process. From the slope of the linear dependency of current peak a1 on the square root of potential sweep rate, and using the RandlesSevcik equation for totally irreversible electron transfer processes, ${ }^{23}$ we can calculate the diffusion coefficient of deferiprone as follows:

$i_{p}=\left(2.99 \times 10^{5}\right) n \alpha^{0.5} A C^{*} D^{0.5} v^{0.5}$

where $\alpha$ is the electron transfer coefficient, $n$ is the number of exchanged electrons, $A$ is the surface area of the working electrode, $C^{*}$ and $D$ are the bulk concentration and diffusion coefficients of the electroreactant species, respectively, and $v$ is the potential sweep rate. The diffusion coefficient of deferiprone was found to be $3.41 \times 10^{-6} \mathrm{~cm}^{2} \mathrm{~s}^{-1}$. It should be added that the peak a 2 current becomes ill-defined at high potential sweep rates due to some accumulation of reaction products generated in the course of peak a1 at the electrode surface.

The effect of $\mathrm{pH}$ on the electrochemical behavior of deferiprone was investigated by cyclic voltammetry using $100 \mathrm{mmol} \mathrm{L}^{-1}$ buffer at various $\mathrm{pH}$ values ranging from 


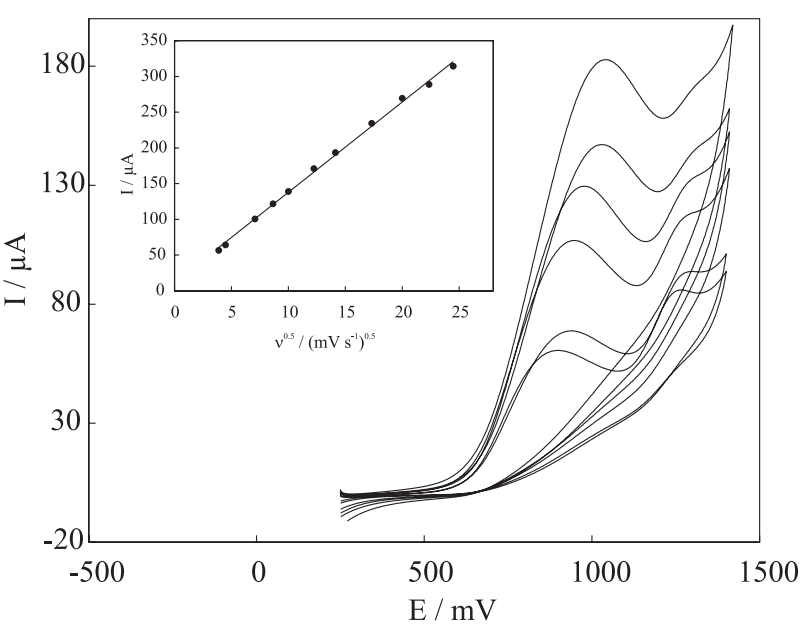

Figure 2. Main panel: Cyclic voltammograms of $15.2 \mathrm{mmol} \mathrm{L}^{-1}$ deferiprone in the acetate buffer solution, $\mathrm{pH}=4.0$ recorded at different potential sweep rates. Potential sweep rates from inner to outer are: 15, 20, 50, 75, 100 and $150 \mathrm{mV} \mathrm{s}^{-1}$. Inset: The dependency of anodic peak current on the square root of potential sweep rate in a wide range of $15-600 \mathrm{mV} \mathrm{s}^{-1}$.

2.3 to 13.1. Figure 3 shows the changes of potential peak a1 with respect to the solution $\mathrm{pH}$. The plot shows that at $\mathrm{pH}<3.2$ and $\mathrm{pH}>10.8$ values, the peak a1 potential remains constant. However, in the range of $3.5<\mathrm{pH}<10.2$, the peak potential shifted to less positive values with $\mathrm{pH}$ values increases. Therefore, it is possible to estimate two $\mathrm{pK}_{\mathrm{a}}$ values for deferiprone, as $\mathrm{pK}_{\mathrm{a}, 1}=3.5$ and $\mathrm{pK}_{\mathrm{a}, 2}=10.2$, from the intersection points in the diagram according to the following acid/base reaction equilibria:<smiles>Cc1c(O)c(O)cc[n+]1C</smiles>

The obtained $\mathrm{pK}_{\mathrm{a}}$ values are in close agreement with those reported in the literature. ${ }^{24,25}$ Moreover, a linear displacement of the peak potential with the $\mathrm{pH}$ of the solution was obtained with a slope of $76 \mathrm{mV} / \mathrm{pH}$ unit in the $\mathrm{pH}$ range of 4.0-10.0 (with a regression equation of $y=-76.35 x+1266, R=0.993, n=9)$. This result indicates the involvement of protons in the electrode reaction, and that the proton-transfer reaction precedes the electrode process.

On the basis of our results (and assuming one can be proposed), we have depicted a mechanism for the oxidation of deferiprone in Scheme 2. In the first step, deferiprone is oxidized to corresponding dione. Then the dione undergoes a probable anodic hydroxylation of the methyl side chain. ${ }^{26}$

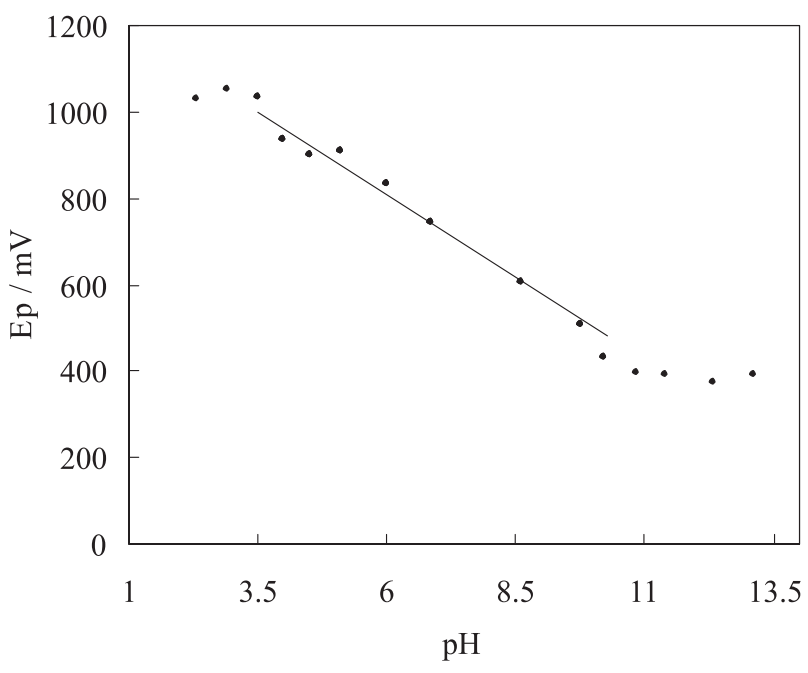

Figure 3. Effect of $\mathrm{pH}$ on the peak potential of oxidation of deferiprone in the acetate buffer solution.

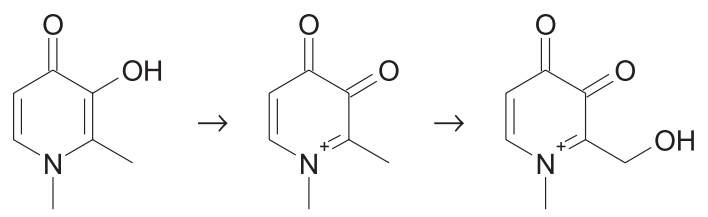

Scheme 2.

The calibration curve for deferiprone in buffer solution, pH 4.0 was obtained by differential pulse voltammetry (DPV). Figure 4 shows typical DPV curves for different concentrations of deferiprone in buffer solution. The dependency between peak current and drug concentration was rectilinear for peak a1 within the range of 0.07 to $0.91 \mathrm{mmol} \mathrm{L}^{-1}$ (with a regression equation of $\mathrm{y}=$ $1.98 x+0.71, R=0.996, n=6$, Figure 4, inset $A$ ), and for peak a2 within the range of 0.10 to $4.12 \mathrm{mmol} \mathrm{L}^{-1}$ (with a regression equation of $\mathrm{y}=1.22 \mathrm{x}+0.54$, $\mathrm{R}=0.996, \mathrm{n}=8$, Figure 4, inset B). The limits of detection (LOD) and quantitation (LOQ) of the procedure were calculated according to the 3 S.D. $/ m$ and 10 S.D. $/ m$ criteria, respectively, where S.D. is the standard deviation of the blank and $m$ is the slope of the calibration curves. ${ }^{27}$ The limits of detection and quantitation were found to be $1.79 \times 10^{-6} \mathrm{~mol} \mathrm{~L}^{-1}$ and $4.71 \times 10^{-6} \mathrm{~mol} \mathrm{~L}^{-1}$ for peak a1, and $2.51 \times 10^{-5} \mathrm{~mol} \mathrm{~L}^{-1}$ and $8.22 \times 10^{-5} \mathrm{~mol} \mathrm{~L}^{-1}$ for peak a2, respectively. Precision and accuracy were assessed by performing replicate analyses of deferiprone samples. The precision of the method was calculated as the relative standard deviation (RSD). The procedure was repeated on the same day on the same spiked solutions at concentrations in the range of the standard series. The intra-assay RSDs of the proposed method, determined on the basis of peak current for 10 replications, were $1.6 \%$ and $1.7 \%$ for peaks a1 and a2, respectively, and showed good repeatability. 


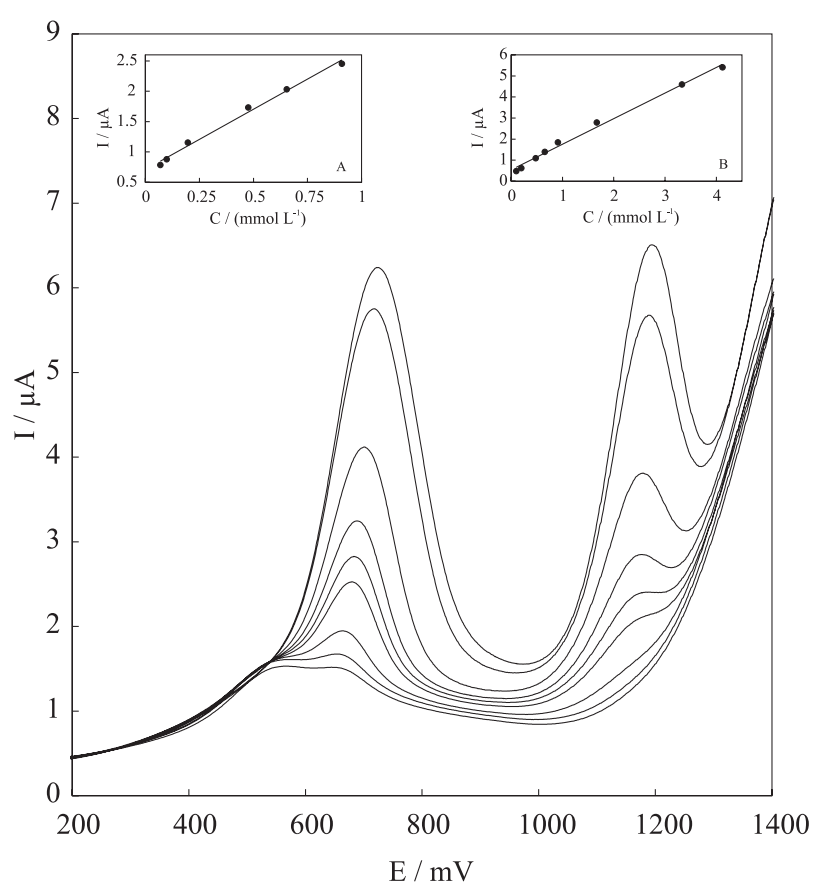

Figure 4. Main panel: Differential pulse voltammograms obtained for determination of deferiprone in the acetate buffer solution, $\mathrm{pH}=4.0$. Deferiprone concentrations from inner to outer are: 0.069, 0.099, 0.196, $0.476,0.654,0.909,1.67,3.33$ and $4.12 \mathrm{mmol} \mathrm{L}^{-1}$. Insets: A: The related calibration graph for peak a1; B: The related calibration graph for peak a2.

The accuracy of the proposed method was determined by spiking serum and urine samples with different concentrations of deferiprone. Good percentage recoveries were obtained from both samples. The analytical parameters obtained for the analyzed samples are summarized in Table 1.

The applicability of the proposed method for the determination of deferiprone in biological fluids was examined by measuring the peak al current as a function of the bulk concentration of the drug in urine and serum (Figure 5) samples. The urine and serum samples were diluted 10 and 20 times with buffer solution of $\mathrm{pH} 4.0$ prior to performing the measurements, to prevent the matrix effect of real samples. The generally poor selectivity of voltammetric techniques can pose problems in the analysis of biological samples, if they contain oxidizable substances. However, no current due to oxidation of the compounds in either the serum or the urine samples appeared. The results obtained from our voltammetric technique for determining deferiprone in serum and urine samples are listed in Table 1. The percentage recovery of deferiprone was determined by comparing the peak currents of a known drug concentration in both media with their equivalents in calibration curves; these results are also summarized in Table 1. Good recoveries of deferiprone were achieved from

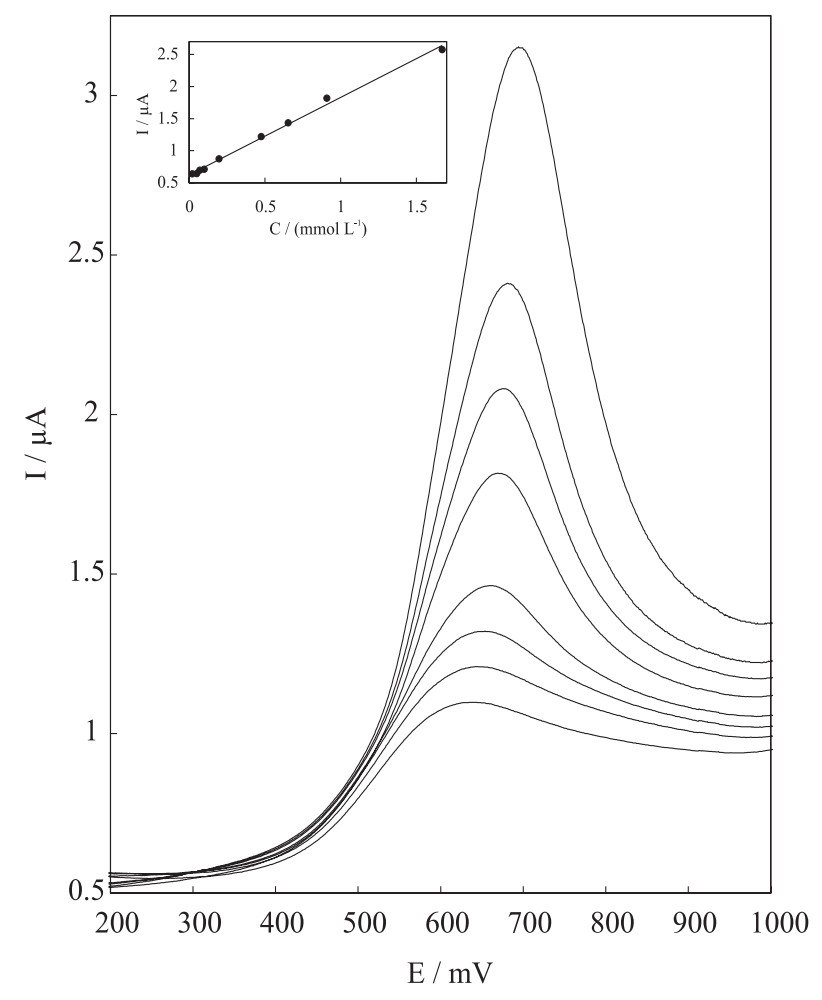

Figure 5. Main panel: Differential pulse voltammograms obtained for determination of deferiprone in the serum sample. Deferiprone concentrations from inner to outer are: $0.05,0.07,0.1,0.2,0.48,0.65$, 0.91 and $1.67 \mathrm{mmol} \mathrm{L}^{-1}$. Inset: A: The related calibration graph.

Table 1. Results obtained for deferiprone analysis from buffer solution and spiked human serum and urine samples and the values reported elsewhere

\begin{tabular}{|c|c|c|c|c|}
\hline \multirow[t]{2}{*}{ Medium } & \multicolumn{2}{|l|}{ Buffer } & \multirow[t]{2}{*}{ Serum } & \multirow[t]{2}{*}{ Urine } \\
\hline & Peak a1 & Peak a2 & & \\
\hline Linearity range/(mol L-1) & $6.95 \times 10^{-5}-9.09 \times 10^{-4}$ & $9.90 \times 10^{-5}-4.12 \times 10^{-3}$ & $5.00 \times 10^{-5}-1.67 \times 10^{-3}$ & $1.96 \times 10^{-4}-4.12 \times 10^{-3}$ \\
\hline Slope $/\left(\mu \mathrm{A}\left(\mathrm{mol} \mathrm{L}^{-1}\right)^{-1}\right)$ & $1.98 \times 10^{3}$ & $1.22 \times 10^{3}$ & $1.21 \times 10^{3}$ & $1.21 \times 10^{3}$ \\
\hline Correlation coefficient (r) & 0.996 & 0.996 & 0.997 & 0.996 \\
\hline R.S.D. $(\%)^{\mathrm{a}}$ & 1.62 & 1.66 & 1.60 & 2.36 \\
\hline $\mathrm{LOD} /\left(\mathrm{mol} \mathrm{L}^{-1}\right)$ & $1.79 \times 10^{-6}\left(8.00 \times 10^{-5}\right)^{b}$ & $2.51 \times 10^{-5}$ & $1.22 \times 10^{-5}$ & $2.31 \times 10^{-5}\left(1.0 \times 10^{-5}\right)^{\mathrm{c}}$ \\
\hline $\mathrm{LOQ} /\left(\mathrm{mol} \mathrm{L}^{-1}\right)$ & $4.71 \times 10^{-6}\left(2.67 \times 10^{-4}\right)^{\mathrm{d}}$ & $8.22 \times 10^{-5}$ & $4.00 \times 10^{-5}$ & $7.72 \times 10^{-5}\left(3.33 \times 10^{-5}\right)^{\mathrm{e}}$ \\
\hline Recovery $(\%)^{\mathrm{f}}$ & & & 99.9 & 99.9 \\
\hline
\end{tabular}

${ }^{\mathrm{a}}$ Each value is obtained from ten experiments; ${ }^{\mathrm{b}}$ The LOD value reported in Ref. 14; ${ }^{\mathrm{c}}$ The LOD value reported in Ref. 15; ${ }^{\mathrm{d}}$ The LOQ value reported in Ref.

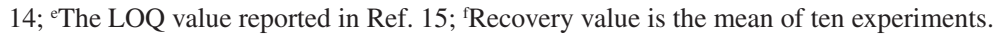


these matrices, meaning that application of our proposed voltammetric method to the analysis of deferiprone in biological fluids could be easily assessed.

In order to evaluate our method in practical analytical applications, quantification of deferiprone in tablet form was attempted. The sample solution prepared as described in Experimental and voltammograms were recorded similar to the case of standard solution of deferiprone. The real sample showed peaks for deferiprone quite similar to the pure sample. The content of deferiprone was calculated from the regression equation, with a $0.64 \%$ difference with respect to the labeled amount.

\section{Conclusions}

The electrochemical behavior of deferiprone was studied in buffer solution on a platinum electrode, using cyclic voltammetry. The kinetic parameters such as the electron transfer coefficient for oxidation and the diffusion coefficient of deferiprone, were determined. A differential pulse voltammetry procedure was optimized and successfully applied for quantification of deferiprone in bulk form, human biological fluids and commercial tablets. The simplicity, sensitivity, selectivity and short time of analysis are the main advantages of these procedures, making them useful for routine analysis.

\section{Acknowledgments}

The financial support of Research Council of K. N. Toosi Univerity of Technology and University of Tehran is gratefully acknowledged. The authors are also grateful to Dr A. Parsaye for his fruitful comments.

\section{References}

1. Kontoghiorghes, G. J.; Pattichis, K.; Neocleous, K.; Kolnagou, A.; Curr. Med. Chem. 2004, 11, 2161.

2. Kontoghiorghes, G. J.; Drugs Today 2001, 37, 23.

3. Paschalidis, I.; Kontoghiorghes, G. J.; J. Radioanal. Nucl. Chem. 1999, 242, 181.

4. Pashalidis, I.; Kontoghiorghes, G. J.; Biomarkers Environ. 2001, 4,80 .

5. Di, J.; Zhang, F.; Zhang, M.; Bi,, S.; Electroanalysis 2004, 16, 644.

6. Georgiou, N. A.; van der Bruggen, T.; Oudshoorn, M.; Nottet, H. S. L. M.; Marx, J. J. M.; van Asbeck, B. S.; J. Infect. Diseases 2000, 181, 484 .
7. Sappey, C.; Boelaert, J. R.; Legrand Poels, S.; Forceille, C.; Favier, A.; Piette, J.; AIDS Res. Hum. Retroviruses 1995, 11, 1049.

8. Hoffbrand, A. V.; Ganeshaguru, K.; Hooton, J. W. L.; Tattersall, M. H. N.; Br. J. Haematol. 1976, 33, 517.

9. Barlett, A. N.; Hoffbrand A. V.; Kontoghiorghes, G. J.; Br. J. Haematol. 1990, 76, 301.

10. A1-Refaie, F. N.; Wonke, B.; Hoffbrand, A. V.; Wickens, D. G.; Nortey, P.; Kontoghiorghes, G. J.; Blood 1992, 80, 593.

11. Fassos, F. F.; Klein, J.; Fernandes, D.; Matsui, D.; Olivieri, N. F.; Koren, G.; Clin. Pharmacol. Ther. 1994, 55, 70.

12. Hoffbrand, A. V.; Kontoghiorghes, G. J.; Drugs Today 1992, $28,149$.

13. Epemolu, R. O.; Singh, S.; Hider, R. C.; Damani, L. A.; J. Chromatogr. 1990, 519, 171.

14. Goddard, J. G.; Kontoghiorghes, G. J.; Clin. Chem. 1990, $36,5$.

15. Dresow, B.; Fischer, R.; Janka, G. E.; Gabbe, E. E.; Fresenius J. Anal. Chem. 1995, 352, 562.

16. Wang, J., ed. In Electroanalytical Techniques in Clinical Chemistry and Laboratory Medicine; VCH Publishers: New York, 1996.

17. Kissenger, P. T.; Heineman, W. R., eds. In Laboratory Techniques in Electroanalytical Chemistry; Marcel Dekker: New York, 1996.

18. Kauffmann, J. M.; Vire, J. C.; Anal. Chim. Acta. 1993, 273, 329.

19. Ozkan, S. A.; Uslu, B.; Sentürk, Z.; Electroanalysis 2004, 16, 231.

20. Ozkan, S. A.; Uslu, B.; Aboul-Enein, H. Y.; Crit. Rev. Anal. Chem. 2003, 33, 155.

21. Smyth, M. R.; Vos, J. G., eds. In Analytical Voltammetry; Elsevier Science Ltd.: Amsterdam, 1992.

22. Yardimci, C.; Ozaltin, N.; Analyst 2001, 126, 361.

23. Bard, A. J.; Faulkner, L. R.; Electrochemical Methods, Wiley: New York, 2001, p. 236.

24. Motekaitis, R. J.; Martell, A. E.; Inorg. Chim. Acta 1991, 183, 71.

25. Kline, M. A.; Orvig, C.; Clin. Chem. 1992, 38, 562.

26. Lund, H.; Hammerich, O. In Organic Electrochemistry; Hammerich, O.; Utley, J. H. P.; Eberson, L., eds.; Marcel Dekker: New York, 1991, ch. 24

27. Miller, J. C.; Miller, J. N.; Statistics for Analytical Chemistry, $4^{\text {th }}$ ed., Ellis-Howood: New York, 1994, p. 115.

Received: April 25, 2007

Web Release Date: June 5, 2008 